Anomalien in Handlungs-

und Entscheidungstheorien 
Ulrich Druwe

Volker Kunz (Hrsg.)

\section{Anomalien in Handlungs- und Entscheidungstheorien}

Springer Fachmedien Wiesbaden GmbH 1998 
Gedruckt auf säurefreiem und altersbeständigem Papier.

ISBN 978-3-8100-1981-3 ISBN 978-3-663-09271-1 (eBook)

DOI 10.1007/978-3-663-09271-1

(C) 1998 Springer Fachmedien Wiesbaden

Ursprünglich erschienen bei Leske + Budrich, Opladen 1998

Das Werk einschließlich aller seiner Teile ist urheberrechtlich geschützt. Jede Verwertung außerhalb der engen Grenzen des Urheberrechtsgesetzes ist ohne Zustimmung des Verlages unzulässig und strafbar. Das gilt insbesondere für Vervielfältigungen, Übersetzungen, Mikroverfilmungen und die Einspeicherung und Verarbeitung in elektronischen Systemen. 


\section{Inhalt}

Einleitung

1. Kausalitätsprobleme in Handlungs- und Entscheidungstheorien

Volker Dreier

2. Die Wissenschaftlichkeit des Rational-ChoiceAnsatzes in der Politikwissenschaft

Kirsten Mensch

3. Anomalien, theoretische Vorentscheidungen

und das Selbstverständnis von Rational-

Choice

Matthias Gsänger

4. Anomalien in der handlungstheoretischen

Erklärung sozialer Prozesse

Volker Kunz

5. Anomalien in der Entscheidungstheorie.

Empirische Evidenz und Konsequenzen

Sonja Haug.

6. Die Bedeutung von Anomalien für die

Theorieentwicklung. Eine Diskussion am

Beispiel der Kooperation im finiten

Gefangenendilemma

Thomas Plümper. 
7. Kooperation als Handlungsgrund im einfachen

Gefangenendilemma

Thomas Schmidt

8. Framing oder Informationsknappheit? Zur

Erklärung der Formulierungseffekte beim

Asian-Disease-Problem

Volker Stocké

9. Kuhhandel oder Rechte in Verhandlungen

Karl Reinhard Lohmann 